\title{
Postscript: What is a debt situation?
}

Joe Deville

\begin{abstract}
Accounting for the geographies of debt may require types of empirical and theoretical analysis sensitive to the integrated character of relations of debt 'situation'. Analysing debt situations opens up the possibility of questioning the manner in which a particular debt encounter or circumstance is composed in its relation to others, the texture of which can fade from view when attempts are made to delimit where an encounter begins or ends, either spatially or temporally. In the process, attention is drawn to the importance of understanding both the situated character of life in debt and the variation in how the binds of debt are constituted, which can on occasion be more fragile than expected.
\end{abstract}

Keywords: debt; credit; repayment; geography; situations; everyday life

To recognize a coat, placed immobile on a chair, a leaping tiger, or an iridescent, precarious soap bubble ... in three seconds, the coat will still be there, the tiger may have killed me, and there exists a duration short enough for the tiger to be said to be "there where it is": the uniqueness of the situation. And there exists a passage of events, a passage of nature, such that I recognise the same bubble situated in distinct events, such that the bubble belongs simultaneously to my past and the experience that has just slipped into the past: continuity in passage. (Stengers, 2011, pp. 90-91)

Isabelle Stengers, in her reading of Alfred North Whitehead, draws attention to at least three challenges we confront when attempting to account for our engagements with the world: ${ }^{i}$ first, the inevitably situated character of the abstractions that we depend upon, second, the fragility of the conclusions that are drawn about the things that present themselves to us, and, third, that immediate experience (both human and not) continually pulls into it and reworks pasts both recent and more distant and distributed. These are all challenges confronted in the papers that make up this special issue as the authors and their interlocuters confront a very specific dimension of experience: life lived in, and occasionally out of, debt.

Take an object that features in Ryan Davey's (2018, this issue) sensitive ethnographic account of the defensive forms of optimism that can characterise the lives of debtors. The object arrives in this case through the letterbox of one of his participants, Pete. It is a postcard, "cut into a kind of cloud shape" [REF], notifying Pete of a recent visit from the water company in pursuit of an unpaid debt. As Davey observes, in this small object debt achieves material form. In fact, materiality quickly becomes tactility, with Pete gaining a small measure of revenge on the otherwise faceless creditor as he rapidly projects the postcard from Davey's hand to the bin, along with some verbal abuse for good measure. This act, combining both a physical and verbal reaction, is for Davey an attempt by Pete to resist the topological reach of the creditor by "spatially fending off' its material incursions. This is part of what Davey 'recognises' in the encounter, to echo Stengers above. But processes of recognition obviously extend beyond the analyst to the two interacting protagonists - creditor and debtor. Just as for Davey, this involves each responding to precisely the kinds of ontological problem Stengers describes. What, actually, is this postcard? And how is it shaped by the relations - both temporal and experiential - that surround and become bound up in it? Yes, the postcard is a debt collection device, of the kind I have analysed elsewhere (Deville, 2015). But as such it is both ambiguous and multiple. How does the creditor wish this object to be recognised? As I have argued, contrary to common 
assumptions, debt collectors often attempt to deploy a varied affective repertoire in their dealings with debtors: attempting not just to provoke worry and fear but sometimes also hope - most obviously that debt may be resolved. Is that what is happening here? Coming as it does from a water company, the cloud postcard presumably is foremost meant to invoke rainwater. But is there an attempt by the company, even as it simultaneously deploys a threat (the postcard refers to potential enforcement action), to come across as a warmer, less intimidating (fluffier?!) organisation than might otherwise be anticipated? If so the attempt fails, with Pete recognising the postcard in a quite different way, as seemingly nothing other than the latest of a litany of coercive prompts from a perhaps indistinguishable group of creditors. The result, as the cloud floats swiftly from hand to bin, is that the object binds to it the immediate and highly contextual past of Pete's interaction with the ethnographer, the legally circumscribed past of Pete's outstanding debt to the water company, and his and indeed others' much longer and more diffuse experiences of dealing with demanding creditors. Analyst, creditor and debtor are each faced with the problem of ascertaining which relations are the most relevant (cf. Savransky, 2016) to the composition of this particular situation.

This encounter between debtor and creditor - mundane, perhaps, but variants of which are likely being re-enacted daily the world over - encapsulates themes that crosscut this special issue. These include the necessity of understanding the temporal politics of debt as resolutely situated, the potential multiplicity of debt, and the capacity, even the tendency, for debt to become bound up with a host of other relations. It is in my view a genuine achievement that the authors in this special issue open up these issues in such a diverse and compelling manner. In what follows, I will explore how, before reflecting on some questions that remain to be addressed in accounting for the geographies of debt and indebtedness via an account of 'relations as capture'. In doing so, I would like to introduce a way of understanding these situated, multiple, relationally composed forms of debt as debt situations.

\section{Debt situations}

As the editors assert in their introduction (Harker and Kirwan, 2018), this collection adds to a growing body of work (cf. Harker, 2017; Peebles, 2012) that deepens our understanding of the agency of the spatial in relation to debt. As they rightly point out, this helps deal with an asymmetry in work on debt, in which there is a tendency to privilege its temporal dimensions over others, leaving the spatial as something of a residual category. Perhaps because I am not a geographer, though, I find myself as hesitant to privilege, or if not privilege then at least reify, the spatial as the temporal. What I personally find particularly valuable in the papers in this issue is the way they add richness to the description of debt situations.

The term situation is pleasingly polysemic: etymologically rooted in notions of place (from the Latin situs, meaning 'place' or 'position'), with some largely historical uses of the word making full use of this history, iii the word now tends to be used in a broader sense, including to refer to 'the state or general circumstances of something at a particular time' (Oxford English Dictionary, 2018). Whitehead, with whom I began, also saw potential in the word as a way of opposing the drive towards 'localisation' in modern science. As Stengers writes:

Localization responds to an 'abstract' question, demanding the abstraction constituted by space, and this question may of course be fruitful, but it cannot under any circumstances relegate to appearances the concrete plurality of the "theres' designated by the 'situation"' (Stengers, 2011, p. 83). 
Whitehead sees modern science, modern philosophy, and by extension a plethora of modern practices, as repeatedly substituting what Stengers here refers to as the 'concrete plurality' of existence for 'misplaced concreteness' (Whitehead, 1985 [1929], p. 64). As this implies, what is at stake is not concreteness per se, but rather the overly hasty and inattentive way in which concreteness tends to be specified. Concreteness for Stengers and Whitehead is to be understood as related not to the primary and secondary qualities of things - the latter, it is conventionally assumed, being projected onto things by the sensing mind/body - but rather to the 'concrete fact of passage' (Stengers, 2011, p. 66). Concreteness becomes mis-placed when a diversely composed world, defined by its continuing 'process' or 'passage' (Whitehead, 2004 [1920]), and a diversely sense-able world (see Halewood, 2011, p. 51), iv is reduced to 'appearances', which can be understood as that which most immediately presents itself to us in perception. The theoretical and scientific apparatuses of localisation are part of this, whose primary purpose is to isolate phenomena in particular times and spaces. Accounting instead for situations, or perhaps rather 'relations of situation' (Stengers, 2011, p. 82), opens up the possibility of questioning the manner in which this or that encounter or circumstance is composed in its relation to others, the delicate texture of which can rapidly fade from the scene in activities designed to delimit where an encounter begins or ends, spatially as much as temporally. In this respect, an analysis of debt situations is very much in keeping with Sam Kirwan's aim to analyse the 'varying intensities and consistencies' that constitute the binds of debt (Kirwan, 2018, this issue, p. XX).

Perhaps nowhere are the relations of debt situation rendered starker and more explicit than in the lives of migrants relocating transnationally under conditions of economic disadvantage. As Kavita Datta and Camille Aznar document in their nuanced analysis of the experiences of Somali, Brazilian, Cameroonian and Congolese migrants in London, debts accrued to fund migration itself - often involving borrowing from family and friends - intersect in dynamic and often difficult ways with locally accrued debts, both informal and formal, ranging from loans associated with local friendship and kinship networks to bank loans, overdrafts and credit card debts. The authors describe these debts as 'multi-stranded' (Datta and Aznar, 2018, this issue, p. $\mathrm{XX}$ ), a term which speaks evocatively to the complexities of interlocking debts, which they also reveal to be tangled with the similarly multi-stranded obligations and responsibilities that characterise migrants' daily lives. As part of this, at one point analyst and research participant recognise financial obligations in not necessarily compatible ways: what on the face of it appear to Datta and Aznar to be 'loans' - in this case from family and clan members living in the country of departure - are not understood as such by number of their participants: "it is not a loan", asserts Abtee, a migrant from Somalia, leaving little room for doubt, "it is Somali culture, when someone is leaving the country he asks his family for help" (Datta and Aznar, 2018, p. $\mathrm{XX}$ ). As the authors observe, such offers of help do come with obligations and expectations (which, as another participant recounts, can in due course become quite aggressively articulated), but it seems that these are seen by Abtee at the point of the interview as being constituted by a characteristic way of life rather the characteristics of a particular financial instrument. This is vivid evidence of the role of the abstractions that are brought to, and inevitably become part of, relations of situation: quite different and potentially equally productive work is done by understanding the relations in play under the sign of either 'loan' or 'Somali culture'. By being quite open about their own divergent understandings of the situation, Datta and Aznar keep the process through which their abstractions are formed as open and provisional (cf. Debaise, 2017, p. 25). 
We should not, however, just rely on individual debtors to challenge our understanding of debt ontologies. Relations of situation operate at and through all scales. The datasets used by Dylan Simone and Alan Walks (Simone and Walks, 2017, this issue) in their analysis of migrant indebtedness in three Canadian cities connect together a large and spatially distributed range of debtors. Through their analysis, diverse and individually situated experiences coalesce into a set of provocative patterns that appear to reveal that these cities are, at least to a degree, witnessing an inversion of conventional debt logics. It is common for many migrant groups to struggle to access mainstream forms of debt, with so-called 'thin' credit files, unsteady employment, and exclusion from the banking system just some of the forces that tend to move new migrants towards forms of 'fringe' finance (Aitken, 2014); indeed we see examples of this provided by Datta and Aznar. However, Simone and Walks show how the introduction of new government policies and programs result in new migrants unexpectedly becoming a tempting new market opportunity for mortgage lenders. Specifically, these programmes provided mortgage issuers forms of insurance to encourage them to offer loans to newly arrived migrants, on the face of it designed to ease the integration of migrants into Canadian society. Simone and Walks judge this rather as an instance of asset-based welfare. The ultimate result, they suggest, is to push migrant groups disproportionally towards being highly indebted, with the ultimate beneficiaries of these new financial flows not being migrant home purchasers, but the already wealthier and more established home sellers.

This analysis does, then, reveal much about the capacity of debt to mould to the characteristics of previously undesirable potential borrowers, provided certain conditions are in place, as well as about the uneven spatial distributions of debt among different groups in Canadian cities. But in addition to that, it also highlights some of the diverse range of entities potentially involved in composing debt situations. In this case it includes a particular (perhaps well-meaning) government policy, the differentiated mobility of particular groups, the category of residential 'newness', the unbalanced flows of wealth from one group to another, and the assumption by certain policy makers - perhaps shared by migrant home buyers - that property ownership is an effective vehicle for delivering social and economic acceptance. Insights from other cases considered in this collection help populate this list further. We have already seen in Datta and Aznar's work the role of families and friends in constituting debt situations. Their role is brought out yet further in Chris Harker, Dareen Sayyad and Reema Shebitha's (2017, this issue) paper, in which we see children modifying the expectations they have of their parents' spending power alongside patriarchal norms of money management that see men making higher value spending decisions while women undertake the bulk of the often invisible and unrecognised work of daily money management. Debt situations are also contingent on what is seen and seeable by debtors. In this context, debt audits, both national and domestic, are shown by Johnna Montgomerie and Daniela Tepe-Belfrage to act a means for debtors to ask profound questions about the debts to which they are apparently beholden including, perhaps most tellingly, 'what is it for?' (2018, this issue, p. XX), as well as enabling them to identify more clearly what their debt situations are composed of, ranging all the way from unpaid emotional labour to the after-effects of government bailouts. Debt advice does something similar, as Kirwan shows, by giving debtors a means to recompose their relationships with certain creditors, although even this possibility is being ever more circumscribed by the increasingly powerful tools available to government agencies looking to collect their outstanding debts. And cutting through all this are affects of various sorts, giving debt situations their intimate and often troubling character: alongside the defensive optimism of debtors highlighted earlier (Davey), we find the stresses that accrue with having to wear debts over the long term (Harker et al.), the anger and recriminations that follow 
particular spending decisions (Harker et al.), the fears and anxieties that arise from the nonpayment of debt (Datta and Aznar), as well as the relief, or at least anticipated relief, of anxiety's negation (Kirwan; Montgomerie and Tepe-Belfrage).

\section{Relations as capture}

Of course, this is an utterly incomplete list of the range of forces that coalesce into debt situations. Nonetheless, it gives some sense of the diverse kinds of entities and relations that we may wish to pay attention to in describing their composition: policies, mobilities, accounting tools and techniques, household relations, feelings. What is most obviously missing from this collection are the internal workings of both credit institutions themselves and government agencies (although Citizens Advice, the focus of Kirwan's research, while not formally a government agency, is often understood as such by its users and receives much of its funding from central government). This is an area where further research is required, to supplement a small but growing range of work (e.g. Vargha, 2011; Lazarus, 2013; Lopes, 2015; McFall, 2014; Ossandón, 2014; Deville, 2015).

I would also like to suggest that accounts of debt situations should attend not just to what relations are implicated in them, but also to the specifics of how, precisely, relations capture one another. All of the entities listed above - not all of which, it should be noted, might be considered as straightforwardly human - may be considered as 'lures' to relationality, or what Whitehead termed 'feeling' (using the term not simply to refer to the parallel domain of human sensation). More specifically, as Didier Debaise eloquently describes, this is an understanding of feeling as "a present activity of integrating the past" (2017, p. 48; original emphasis). Relations of situation involve not a discrete assortment of interacting entities but entities both human and not that integrate each other over and over again, in the present, in relation to an ever-changing past and, indeed, to past possibilities that remain unrealised (Debaise, 2017, p. 52). Relations, feelings, or what Whitehead also described as 'prehensions', do not just touch, they grasp, they grip, they interlock, they meld, they recompose. Markets have us (McFall and Deville, 2018). ${ }^{\mathrm{v}}$ Debt markets, reinforced as they are by contract law and a range of norms and socio-technical practices, have us more securely than most. In this special issue this becomes most evident in the moving descriptions provided by debtors themselves of the tight hold of debt over their lives:

the first thing I did when I had a bit of money was to run to the bank and pay... since this day I am scared, I can't find peace (Geneviève, in Datta and Aznar);

The loan is like one of the family members. It eats and drinks with me, and it sleeps and wakes up with us" (Im Ghassan, in Harker et al.);

I always try to keep calm. It's just the debt that makes me feel nervous (Ziad, in Harker et al.).

In such accounts, we see the extent to which debt situates and is situated. The potentially anxious body, the intimacies of household life, the movements of the debtor through the passage of the everyday, each have the potential to simultaneously reach out to and be disturbed by the inevitably unique but nonetheless familiarly patterned series relations that bind and recompose debtor, creditor, and a diversity of other actors inbetween. At the same time, markets rarely have us completely. Debt can be vulnerable to forces that disrupt its passage. As Montgomerie and Tepe-Belfrage observe, paradoxically both paying and not paying debts can be understood as resisting debts insistent logics. Rapid repayment, should funds allow, allows debtors to escape spiralling interest costs, while non-payment, particularly if practiced by not just individuals but populations of debtors, is the spectre that haunts the debt economy. 
Typically, however, debtors cannot see any way to avoid repaying their debts. Partly this is about the sanctions that creditors have at their disposal. But it is often more about the emotional cost that a debtor would incur in by attempting to do so, coupled with the calculative asymmetries that tend to characterise the creditor-debtor relation (cf. Deville, 2015, p. 174). Yet, returning again to Davey's ethnography, this makes the stance taken by his participants all the more remarkable. Implicitly and explicitly they challenge the presumption that debts do, in fact, have to be repaid. This, for Davey, is a challenge to what he calls 'debt realism', in which a binary is invoked with repayment on one side and the illusion of escape on the other. While for many it is not possible to avoid repayment, it is nonetheless possible. Davey's participants do more than cling to this possibility: they amplify it. Through both their imaginative effort and the curation of their domestic relations, Davey shows them as far more in control of how their debt situations are composed - at least as it is experienced in the immediacy of the present - than might reasonably be expected. Debt, in these instances, does not capture but is captured.

Holding onto ideas of what might be and indeed what could have been are ways to move beyond an account of the debt economy as a relentless, inescapable juggernaut. Debt might be more fragile than we assume. A vital task for geographers of debt alongside all their social scientific colleagues is to hold open the possibility of this fragility, to look for its emergence, to imagine what might be otherwise in our relations with debt. The achievement of this special issue is to both begin to do so while so vividly describing what is at stake. As such, I hope that it captures others as effectively as it captured me.

\section{Acknowledgements}

Many thanks to Chris Harker and Sarah Hall for comments on a draft of this paper and to Chris Harker and Sam Kirwan for the invitation to contribute to this Special Issue.

\section{Notes}

i This is an admittedly humancentric rendition of Whitehead: 'we' and 'our' should properly be understood to extend to entities of various sorts.

ii The notion attempts something analogous to Harker's (2017) 'debt ecologies', in seeking to account for debt more relationally. One distinction is that whereas Harker is most centrally interested in using debt ecologies to argue for a 'more-than-economic' geography, sensitive to the diverse social relations to compose and become entangled in economic situations, working with a Whiteheadian-inspired notion of situation might help point towards a different way of thinking relationality, as not just more-than-human but in which the world reaches out to us as much as we reach out to it. I expand on this in the conclusion (see also Deville, 2015, pp. 35-40).

iii As in the following simultaneously evocative and troubling example provided by the Oxford English Dictionary:

"The Citie of Mexico is seated in the same Lake, although the Spaniards have filled vp the place of the scituation with earth" (Oxford English Dictionary, 2018; citing de Acosta, 1604, p. 172)

iv And here 'the manner of theoretical characterization' (Stengers, 2008, p. 51; see also: Savransky, 2016) of a situation matters hugely.

v Thanks to Liz McFall for helping me thinking through the role of possession in constituting market relations, which she does primarily via the work of Gabriel Tarde rather than Whitehead. The commonalities between the two in relation to possession are described by Debaise (2017, pp. 48-9).

\section{References}

de Acosta, J. (1604) The naturall and morall historie of the East and West Indies. 1st edn. Translated by

E. Grimeston. London: V. Sims for E. Blount and W. Aspley.

Aitken, R. (2014) Fringe Finance: Crossing and Contesting the Borders of Global Capital. Abingdon \&

New York: Routledge. 
Final Accepted Manuscript. For publication in Geoforum in the 'Geographies of Debt' special issue, edited by

Chris Harker and Sam Kirwan.

Datta, K. and Aznar, C. (2018) 'The space-times of migration and debt: Re-positioning migrants' debt and credit practices and institutions in, and through, London', Geoforum. doi:

10.1016/j.geoforum.2018.07.009.

Davey, R. (2018) 'Mise en scène: The make-believe space of over-indebted optimism', Geoforum.

Debaise, D. (2017) Nature as Event: The Lure of the Possible. Durham, NC \& London: Duke University Press.

Deville, J. (2015) Lived Economies of Default: Consumer Credit, Debt Collection and the Capture of Affect. London: Routledge.

Halewood, M. (2011) A. N. Whitehead and Social Theory: Tracing a Culture of Thought. London: Anthem Press.

Harker, C. (2017) 'Debt space: Topologies, ecologies and Ramallah, Palestine', Environment and Planning D: Society and Space, 35(4), pp. 600-619. doi: 10.1177/0263775816686973.

Harker, C. and Kirwan, S. (2018) 'Introduction: Geographies of debt and indebtedness', Geoforum.

Kirwan, S. (2018) 'On "those who shout the loudest": Debt advice and the work of disrupting attachments', Geoforum.

Lazarus, J. (2013) L'Épreuve de l'Argent. Banques, banquiers, clients. Paris: Calmann-Lévy.

Lopes, D. S. (2015) 'Credit (re)connections', Cultural Studies, 29(5-6), pp. 827-844. doi: 10.1080/09502386.2015.1017146.

McFall, L. (2014) Devising Consumption: Cultural Economies of Insurance, Credit and Spending. London: Routledge.

McFall, L. and Deville, J. (2018) 'The market will have you: The arts of market attachment in a digital economy', in Cochoy, F., Deville, J., and McFall, L. (eds) Markets and the Arts of Attachment. Abingdon \& New York: Routledge, pp. 108-131.

Montgomerie, J. and Tepe-Belfrage, D. (2018) 'Spaces of debt resistance and the contemporary politics of financialised capitalism', Geoforum. doi: 10.1016/j.geoforum.2018.05.012.

Ossandón, J. (2014) 'Sowing consumers in the garden of mass retailing in Chile', Consumption Markets \& Culture, 17(5), pp. 429-447. doi: 10.1080/10253866.2013.849591.

Oxford English Dictionary (2018) 'Situation, n.', OED Online. Oxford: Oxford University Press. Available at: http://www.oed.com.ezproxy.lancs.ac.uk/view/Entry/180520 (Accessed: 27 September 2018).

Peebles, G. (2012) 'Whitewashing and leg-bailing: On the spatiality of debt', Social Anthropology, 20(4), pp. 429-443. doi: 10.1111/j.1469-8676.2012.00221.x.

Savransky, M. (2016) Adventure of Relevance: An Ethics of Social Inquiry. London: Palgrave MacMillan.

Simone, D. and Walks, A. (2017) 'Immigration, race, mortgage lending, and the geography of debt in Canada's global cities', Geoforum. doi: 10.1016/j.geoforum.2017.10.006.

Stengers, I. (2008) 'Experimenting with refrains: Subjectivity and the challenge of escaping modern dualism', Subjectivity, 22(1), pp. 38-59. doi: 10.1057/sub.2008.6.

Stengers, I. (2011) Thinking with Whitehead: A Free and Wild Creation of Concepts. Cambridge, MA; London: Harvard University Press.

Vargha, Z. (2011) 'From long-term savings to instant mortgages: Financial demonstration and the role of interaction in markets', Organization, 18(2), pp. 215-235. doi: $10.1177 / 1350508410392100$.

Whitehead, A. N. (1985) Science and the Modern World. London: Free Association Books.

Whitehead, A. N. (2004) The Concept of Nature. New York: Prometheus Books. 
Final Accepted Manuscript. For publication in Geoforum in the 'Geographies of Debt' special issue, edited by Chris Harker and Sam Kinvan. 